\title{
AGUSTÍ VEHÍ, LA HISTÒRIA PER ENTENDRE-HO TOT ${ }^{11}$ Jordi Figuerola Garreta Universitat Autònoma de Barcelona
}

\begin{abstract}
De manera que els policies escrivim, si més no, un servidor, sobre la realitat que veiem quan treballem, una realitat complexa, sorprenent, inesperada, canviant, desconcertant, estranya i, per descomptat, prodigiosa. I una realitat que tenim sempre davant, no la coneixem a través dels diaris o dels informatius; és davant nostre cada dia, $\mathrm{amb}$ tota la seva força i potència, aquest és un dels grans privilegis del policia: observar, des de primera fila, a l'ésser humà en societat, quadrilla, nocturnitat, premeditació $i$ traïdoria. Parlem de la pura realitat perquè hi treballem, inevitablement. I, d'aquesta forma d'escriure, en direm novel.la negra? Sí, si es vol. Sembla quasi obligat que, parlant de crims i de policies hagi de ser així: perquè parlem de la nostra realitat professional, del que coneixem, del que sabem. Molt bé. (VEHÍ: 2012b)
\end{abstract}

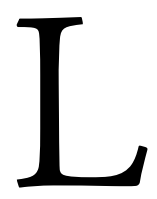

a mort es va endur l'Agustí Vehí en plena maduresa personal i creativa. Malgrat que l'autor tingués una producció escrita anterior amb articles, llibres de recerca històrica i d'altres, el que comprèn el seu corpus novel-lístic de gènere negre són cinc obres publicades en els darrers cinc anys: Abans del silenci (2009), Ginesta pels morts. Un blues empordanès (2010), Quan la nit mata el dia (2011), Torn de nit. Un vodevil negre i policial a l'empordanesa (2012) i Remor de serps (2013), aquesta última apareguda pocs mesos després del seu traspàs.

Si exceptuem Torn de nit, les altres quatre configuren un conjunt amb característiques semblants quant a l'estructura, el discurs narratiu, els elements argumentals, els trets definidors de l'originalitat de l'autor i els tòpics novel.lístics personals. Esdevenen, de fet, un corpus original, personalíssim, que ens ensenya fins a quin punt la irrupció de l'Agustí Vehí en la novel-lística tenia al darrere un pòsit de reflexió, tècnica $i$ coherència. Aspectes que ens explicarien l'estil perfilat, la maduresa

${ }^{11}$ Per a tu, Agustí, amic meu, i gràcies per tantes coses. 
creativa i el domini literari de la imaginació de l'autor. Amb l'atreviment que suposa especular sobre una cosa que no es produirà mai, diria que aquestes obres haurien estat el preludi d'unes de posteriors, impossibles ara, amb temàtiques de fons que l'Agustí podia concebre, però que encara exigien un aprenentatge més dilatat. Per tant, les novel.les publicades per Vehí, per més que siguin «rodones», utilitzant un argot de llenguatge comú, no serien el punt culminant d'un treball anterior, sinó l'inici d'una carrera literària molt més ambiciosa i complexa que, dissortadament, no podrà ser.

\section{L'UNIFORME I L'ESCENARI DE LA CREACIÓ}

La biografia de l'Agustí Vehí ens explica moltes coses d'ell com a novel.lista i encara ens el fa més atractiu a nivell literari. La seva fou una vida dedicada a la policia local amb diferents responsabilitats fins a la de sotsinspector de la Guàrdia Urbana de Figueres durant molts anys. Un policia-escriptor, un «urbano» que reflexionava d'aquesta manera sobre la dedicació a la literatura:

Suposo que moltes persones, seran de l'opinió que, el fet que algú escrigui, ja es prou pega, entre d'altres coses perquè sempre hi haurà qui ho pugui llegir i la cosa, escriure i llegir, es pot estendre perillosament entre la població que, innocent, pot arribar, sense adonar-sén, a la màxima perversitat possible: pensar i tenir opinió pròpia. Si aquesta possibilitat no és prou alarmant, cal afegir l'agreujant que, a més a més, qui ho fa és un funcionari uniformat i encarregat, per més calamitat, de fer complir les lleis i garantir l'ordre públic. Llavors el desastre pot prendre proporcions de catàstrofe, esdevenir una fatalitat, una mena d'adversitat que, en temps del generalísimo, era absolutament impossible, impensable, inimaginable. (VEHÍ: 2012b)

Però l'Agustí Vehí no era un policia normal i corrent — que a hores lliures escrivia novel.les com una mena de distracció o d'evasió- sinó que fou un professional que va reflexionar, teoritzar i escriure abastament sobre la seguretat i la tasca policial. I per dibuixar com havia de ser el policia i el seu treball en el moment actual, o quin model policial calia al país i a les viles de casa nostra, lligava els coneixements tècnics policials, el sentit comú, l'anàlisi sobre d'on venien els policies en la història recent, 
les necessitats socials presents i l'estudi de les transformacions profundes de la societat:

Una cosa és certa: quan el procés que denominem «la transició» es va iniciar i, entre tots, vam començar a refer les institucions de les quals ara gaudim amb tota normalitat, no hi havia record, a casa nostra, del funcionament i les relacions, interiors i exteriors, que havien de regir collectius uniformats i jerarquitzats. Malgrat saber perfectament quina cosa no volíem, els referents inevitables, inconscients, eren un exèrcit que havia guanyat una guerra civil i una policia que havia servit amb fidelitat el general. La lenta, accidentada i difícil incorporació de les dones a la funció policial és un bon exemple del que dic. I alguna cosa en queda, tènue, imprecisa, si es vol, però queda (tota una altra cosa és un fet prou terrible: quan el passat es comença a esvair, arriben les noves formes de militarisme i totalitarisme, populisme i xenofòbia). Alguna cosa queda, dèiem. Així, aspectes com la llibertat d'expressió, la sana i educada discrepància o la reflexió intel.lectual sobre la professió, no acaben de trobar taula parada a la nostra policia, si més no, taula parada amb normalitat i de manera quotidiana. Per això, i des de la policia, no són habituals textos que pensin la professió, o la funció, o la institució, o la formació, o que facin propostes innovadores i adequades a les noves realitats socials que (...) arriben a unes velocitats esfereïdores i es queden, interactuant amb les existents i creant, constantment, una cosa nova. (VEHÍ: 2012b)

Probablement, l'escriptor figuerenc fou un dels professionals que més clar tenien això que s'anomena, tècnicament, «un policia de proximitat», un servidor públic respectuós amb les diferències i les llibertats. Una veu que sempre defensà models policials innovadors, cosa que alguna vegada, li comportà algun problema ${ }^{12}$. Anys després reflexionava sobre aquest fet tot dient:

no és massa habitual que un policia escrigui i, més preocupant encara, no és corrent que reflexioni en veu alta sobre la seva professió. I un dels factors probables d'aquesta situació són els referents franquistes sobre els cossos jerarquitzats, les opinions i els comportaments que han de tenir, i són esperables, dels ciutadans

${ }^{12}$ Com quan va publicar el famós article «D’Urbanos, grans superfícies i models policials», que va sortir publicat a El Punt, pel juliol del 2001, on plantejava un seguit de qüestions molt interessants sobre el model policial català i el concepte de Policia de Catalunya. Es pot consultar a: http://webpolicial.info/portal/index.php?option=com_ content $\&$ task $=$ view $\&$ id $=658 \&$ Itemid $=2$ 
que treballem d'uniforme. Uns referents que, en la meva opinió, encara cuegen, més ben maquillats o menys, més evidents o no. (VEHÍ: 2012b)

L'Agustí Vehí va entrar a la policia en plena restauració democràtica empès per crear un model de seguretat $i$ uns professionals respectuosos amb les lleis, d'esperit democràtic i amb clara voluntat de servei al país. Darrere hi havia un compromís amb la llibertat i d'ajudar a perfilar la tasca que havien de dur a terme els cossos de seguretat en aquest nou context. I, és evident, com es pot suposar, que la policia era uns dels collectius amb més inèrcies franquistes $i$ on la feina de fer prevaler actituds democràtiques era, probablement, més difícil. La illlusió i els tips de treballar de la generació de policies com ell, sovint poc reconeguts, per fer prevaler actituds democràtiques en la policia fou gegantina. Aquesta preocupació la va tenir sempre el policia-escriptor i, per això, no ens podem estranyar que el febrer de 2012 plantegés un tema crucial:

saber quines restes de comportaments propis de la dictadura, d'allò que podríem definir com actituds preconstitucionals, queden enmig dels membres de més edat dels diferents cossos i forces de seguretat $i$, molt més important encara, si existeixen mecanismes per a detectar, en els seus membres més joves, la presència de les noves formes de pensament o comportament totalitari que treuen el nas arreu d'Europa. Si convenim, entre altres coses, que el feixisme és un estat d'ànim, haurem de poder aclarir, per pura salut democràtica, si és present o no a les nostres institucions policials, ni que sigui com a possibilitat. (VEHÍ: 2012b)

Però al costat de tot el que estem dient, pouava el concepte i la definició del que és un policia des d'un profund humanisme. Ell mateix ens ho explica de manera deliciosa i commovedora, a través d'una sensibilitat i d'una humanitat de fons que impregnarà la seva literatura:

I, primer de tot, qui és exactament un policia? Suposo que, més enllà de les definicions canòniques de lleis, reglaments i textos institucionals, convindrem, per damunt de tot, en que un policia hauria de ser un gestor de les passions humanes, des de les més quotidianes fins les més extremes, una feina gens fàcil, certament. Un mediador entre formes cada dia més diferents d'entendre la vida i la convivència. Algú que ajuda i guia. Algú que facilita la recuperació de la normalitat quan aquesta es trenca, algú que reeduca, algú que evita, algú que salva. (...) Però jo, que només sóc un petit i feliç guàrdia urbà del meu poble, també penso 


\section{Revista de Filologia}

que ser policia és somriure en el pas de zebra a una persona gran que passa. Potser serà l'únic somriure que li facin en tot el dia. (VEHÍ: 2012b)

Canviem de camí i, dins d'aquest perfil biogràfic, parlem una mica de geografia. Si en el gènere negre és parla de l'escenari del crim, hem de convenir, doncs, sense cap mena de dubte, que «l'escenari de la creació» de l'Agustí Vehí és la seva casa de Pont de Molins, on vivia. De fet, hi ha una relació estreta entre quan hi va viure i la producció literària més prolífica. Una casa, davant del riu la Muga, amb una màgia especial, típica del poble, amb una porta petita que t'endinsa cap a una escala, d'on surten les estances $i$ les habitacions a diferents nivells, i una sala, amb el jardí al fons i la llar de foc a la paret, i la presència d'infinitats de records - de fet, de tots els records-, com les ampolles de calvados que s'han begut en moltíssims sopars amb amics i en la intimitat. Una casa «viscuda», de flaire que s'està cuinant - la Marie naturalment-; un lloc on s'hi concentra tot un univers, com els baixos on l'autor hi tenia la biblioteca $i$ escrivia -el seu espai, castell i fortalesa, refugi i Parnasse-, ple de llibres, papers, revistes, cascs policials, fotografies, esquemes de novel.les, mapes penjats i coses, hores d'ara, inconfessables. Un veritable atelier per a un escriptor i un intel.lectual, sense el qual, veritablement, no es pot entendre el novel.lista i la seva obra.

\section{LA HISTÒRIA, UNA PRIMERA PISTA}

En totes les novel.les d'Agustí Vehí hi ha la història com un element clau i el fet històric com un tret essencial de la trama. És una obvietat que un marc temporal sol ser sempre al darrere de qualsevol creació de gènere negre. Però en les obres de Vehí es tracta del fet històric precís, minuciós, la història que esdevé una protagonista fonamental al costat dels altres protagonistes de carn i ossos. Quines serien les raons per les quals és tan important en la seva narrativa? Probablement dues: primera, el coneixement profund que tenia de la història i, segona, la necessitat, a nivell novel.lístic, que li caracteritzés l'evolució dels personatges; en marqués, en el sentit dels clàssics, el destí.

Comencem per la primera raó. L'escriptor, a part d'agradar-li de sempre la història, la va convertir en el seu focus de coneixement científic. 
Això es percep en les seves novel-les $i$ en les seves diverses facetes intel.lectuals, a part de la literatura. Llicenciat i Doctor en Història, fou, a més, un home educat en un coneixement ampli de la matèria: format com a medievalista, va fer una tesina i una tesi doctoral d'història contemporània i exercí de professor de l'evolució de la seguretat pública i del fenomen policial al llarg dels temps. Per tant, gaudia d'una preparació acadèmica més que notable en aquesta camp i, alhora, tenia molt clar quin tipus d'història li interessava:

Explicar Història sempre: a classe amb la veu, a les novel.les amb la paraula escrita. Història quotidiana, petita, de vides inventades que volen ser reals $i$, a través de les quals, es pugui dibuixar la gran Història a fi que es conegui de manera amable, en el decurs d'un relat novel.lesc, com qui no vol, però que s'acabi coneixent. ${ }^{13}$ (VEHÍ: 2012b)

En la seva tesi doctoral, presentada a la Universitat Autònoma de Barcelona el 2006, amb el títol de Torna el fusell i posa't a treballar. La Milícia Nacional a Figueres a la darrera guerra carlina $(1872-1876)^{14}$, fa una descripció minuciosa i precisa d'una guàrdia local liberal que va

\footnotetext{
${ }^{13}$ En el mateix text hi ha un paràgraf molt divertit sobre el fet de «ser d'Història»: «Un servidor, diguem-ho d'una vegada, encara té un secret per confessar, i prou terrible: és d'Història! Sí, és així. Aquest fet, al costat que porti trenta anys al cos i tingui alguna graduació, diu molt poc en favor dels criteris de selecció en el moment de l'ingrés i, encara menys, de l'eficàcia dels mecanismes d'ascens. És obvi que les persones encarregades de tot això no estan pel que han d'estar i, les autoritats, ja fa temps que hi haurien d'haver pres cartes en l'assumpte. Que no ho hagin fet és la mostra palpable i evident que dormen de manera permanent o són a l'hort a totes hores.»

${ }^{14}$ Publicada per l'Ajuntament de Figueres amb aquest mateix títol en la col-lecció «Juncària»:, el desembre del 2008. El fet de ser el director de la tesi és el que fa que m'atreveixi a fer aquestes quatre ratlles sobre la importància de la història en la novel-lística d'Agustí Vehí. He de confessar que el procés d'elaboració de la tesi fou plàcid i vaig aprendre moltes coses. Només vàrem discutir sobre el títol. Ell, amb el seu esperit de novel.lista, volia titular-la Torna el fusell i posa't a treballar. Jo, com a acadèmic, no ho volia, perquè considerava que aquest títol no servia per identificar el contingut de la recerca en qualsevol repertori bibliogràfic sobre història entre els especialistes. Finalment, i per sort, va mantenir-se en la seva posició — ara em sembla un títol delicióstot i que va transigir que s'hi afegís, per imperatiu meu, La Milícia Nacional a Figueres a la darrera guerra carlina (1872-1876).
} 
defensar Figueres en un moment històric crucial. La tesi no és un exercici intel-lectual perquè sí, sinó que resumeix perfectament el que l'atreia més de l'anàlisi històrica $i$ on apareixen els tres elements que li interessaven més en iniciar aquesta investigació: uns guàrdies, homes de carn i ossos, que defensen una causa progressista i local; un lloc on passen els esdeveniments, la seva estimada Figueres, i una conjuntura històrica que marca el destí d'aquests guàrdies i d'aquesta ciutat. I és curiós perquè, per raons històriques, no deixa de ser la crònica d'uns perdedors i l'esfondrament d'un projecte - en plena Primera República - de canvi d'una realitat feixuga com aquella a què havia abocat el moderantisme espanyol. El text de la tesi és científic i acadèmic, però la redacció és clarament la d'una persona que, mitjançant l'escriptura, ens vol transmetre els aspectes vivencials dels subjectes històrics. I, de fet, la càrrega literària i poètica es pot veure en l'últim paràgraf de la tesi, quan parla del destí d'aquells milicians als quals, malgrat haver defensat Figueres, la nova conjuntura de la Restauració aparta de la feina:

La ratlla que aquests homes no passen mai potser és molt evident i casolana, potser pren la forma d'un plat a taula; és a dir, el 1876, esdevinguda ja la revolució un somni inabastable per al poble, es va fer realitat el títol d'aquest llibre: torna el fusell i posa't a treballar. (VEHÍ: 2008, 264)

O sigui, uns perdedors de la «revolució inabastable»: que deixen el fusell $i$ es posen a treballar $i$, tot plegat, per una qüestió tan simple com la de tenir un plat a taula. Com podem veure, és la història que explica l'esdevenidor amb rostre humà i que ens mostra la humanitat dels protagonistes. Hi ha molts tipus d'historiadors científics i molts aspectes de recerca: a uns els agrada trobar la ciència o la teoria; a d'altres, els agrada trobar la gent. A l'Agustí Vehí li apassionava aquest segon aspecte: trobar la gent, percebre en els cossos l'esdevenir inexorable del destí històric. Durant la lectura i exposició pública de la tesi, un membre del tribunal es va passar molta estona parlant de teories, de models policials amb referència als EEUU i a mig món, i no va adonar-se ni va citar coses de la tesi que tenien un valor incalculable, com haver estat capaç, l'Agustí, de trobar la fortificació urbana des d'on la milícia disparava. És aquesta la diferència entre aquells que fan ciència per la ciència i aquells que, com 
l'Agustí Vehí, feien ciència per descobrir com vivia la gent, què els passava, quin era el seu univers mental, per quins sentiments els bategava el cor, i tantes altres coses d'una dimensió humana i històrica indubtable.

Escriure li resultava una experiència singular, però donar classes l'omplia d'una manera especial. Com a professor d'història era, senzillament, brillant, un gran pedagog, irònic i enginyós, a qui apassionava el contacte amb els alumnes $i$ que, com a home de principis, explicava la ciència a partir d'una ètica compromesa en actituds i comportaments democràtics i progressistes. Ser professor, per a ell,

Vol dir, primer de tot, ser molt feliç: ajudar a entendre el passat, a desllorigar els processos històrics, aprendre als costat dels alumnes amb les seves preguntes $i$ els seus raonaments, reflexionar preparant les classes..., és un exercici personal i intel.lectual meravellós, apassionant. Però també vol dir, entre moltes altres coses, constatar l'estat del coneixement de la nostra història entre els estudiants. No direm res d'això, no és el moment. I, sobre tot, del coneixement de la història més propera, la que pot ajudar més a entendre el nostre present, els nostres dies. (VEHÎ: 2012b).

Va donar classes durant molts anys a l'Institut de Seguretat Pública de Catalunya en l'assignatura «Història de Catalunya i de la Policia», i, de fet, en la novel.la Ginesta pels morts, hi ha una dedicatòria «a tots els alumnes que he tingut, al llarg dels anys, a l'Institut de Seguretat Pública de Catalunya: unes tardes inoblidables i meravelloses en què, amb humor i rigor, intentàvem descobrir què ha estat la història del nostres país ${ }^{15}$ (VEHÍ; 2010, 7). Com a docent el seu cas és singular, i de ben segur únic, en les universitats de casa nostra, ja que també donava classes a l'Escola de Prevenció i Seguretat Integral (EPSI) de la Universitat Autònoma de Barcelona. Ell, a través del paraigua de la història, podia parlar dels temes de «seguretat» des de diferents perspectives: la policial, la jurídica, la psicològica, la sociològica, la tècnica, etc., que tan bé coneixia gràcies a la seva pràctica professional i de comandament.

\footnotetext{
${ }^{15}$ Vaig compartir amb l'Agustí Vehí la docència a l'Escola de Policia de Catalunya de Mollet del Vallès (ara ISPC) sobre història de la policia i de Catalunya durant molts anys i puc donar testimoni sobre el que significava per a ell l'aprenentatge i la preparació de materials per fer les classes.
} 
I aquesta dedicació a l'ensenyament també es nota en la seva literatura. Per exemple, hi ha un detall en l'última novel.la, Remor de serps, que difícilment trobarem en d'altres novel.listes. Quan un dels protagonistes, el comandant de la Guàrdia Civil, Domènech Roig, es veu interpel.lat sobre què farà davant un fet concret, respon:

—Encara no ho sé. Però segurament seguiré el consell d'un vell amic meu: «El guàrdia civil serà prudent sense debilitat, ferm sense violència i polític sense baixesa. No ha de ser temut sinó dels malfactors, ni temible sinó als enemics de l'ordre».

- Ja. Molt bonic per a les desfilades, però si us foten quatre bufetades, què?

-Doncs faré cas al que diu sempre un altre conegut: «Les seves primeres armes han de ser la persuasió i la força moral, recorrent a les que porti a sobre només quan es vegi ofès per altres a les seves paraules no hagin estat suficients. E aquest cas, deixarà sempre ben posat l'honor de les armes».

-Cony! I qui són aquests coneguts vostres?

-Oh, el sis i el set.

-El sis i el set? És que no tenen nom?

—No, són dos articles de la cartilla de la Guàrdia Civil. Sempre va bé recordar qui ets, sobretot si poden venir mal dades. I ara, anem per feina. (VEHÍ: 2013, 40).

O sigui, es recorda de la Cartilla de la Guàrdia Civil, text redactat pel Duque de Ahumada el 1845 i que, tenint en compte l'època en què va ser escrit, és molt interessant, tant pel que diu com per les novetats policials que aporta. Doncs bé, l’Agustí Vehí, en els seus apunts d'història de les forces d'ordre públic, sempre posava aquest text, i formava part de les explicacions a classes. Era un tema sobre el qual havia treballat molt amb els alumnes.

La necessitat d'explicar història representava un compromís ètic per no perdre la memòria. Un mestre d'historiadors com Hobsbawm, en el llibre que resumeix la història del segle XX, ens advertia que:

La destrucción del pasado, o más bien de los mecanismos sociales que vinculan la experiencia contemporánea del individuo con la de generaciones anteriores, es uno de los fenómenos más característicos y extraños de las postrimerías del siglo XX. En su mayor parte, los jóvenes, hombres y mujeres, de este final de siglo crecen en una suerte de presente permanente sin relación orgánica alguna con el pasado del tiempo en el que viven. Esto otorga a los historiadores, cuya tarea con- 
siste en recordar lo que otros olvidan, mayor trascendencia que la que han tenido nunca, en estos años finales del segundo milenio. Pero por esa misma razón deben ser algo más que simples cronista, recordadores y compiladores, aunque esta sea también una función necesaria de los historiadores. (HOBSBAWM: 1995, 13).

Una preocupació que, ben segur, tenia el mateix Agustí Vehí quan afirmava que «és obvi (...) que cal explicar Història constantment, a totes hores, a tots els llocs possibles i amb tots els mitjans disponibles» (VEHí; 2012b). I, de fet, la novel.lística li servia per fer aquesta tasca de recuperar la memòria i no contribuir a la destrucció del passat,

Però la història, com hem dit anteriorment, és fonamental en l'obra de l'Agustí Vehí per una segona raó que volem destacar: la necessitat que té l'autor que marqui l'evolució dels personatges i esdevingui el marc temporal i referencial del seu destí. En aquest sentit, esdevé un protagonista més de les novel.les, un protagonista actiu que dibuixa i perfila la humanitat d'uns personatges senyalats per la conjuntura que els ha tocat viure. A diferència de les tragèdies gregues —on el destí marca la vida, sovint tràgica, dels protagonistes i del qual no es poden salvar- la concepció de la història que hi ha al darrere de les obres de Vehí és que, malgrat no tén puguis escapar, sempre hi ha uns elements que situen els personatges per damunt de la dissort o de la brutalitat del moment històric. Aquests elements serien dos, segons el nostre entendre: els valors ètics i la manera d'entendre la vida i el món, d'una banda, i els sentiments, l'amor, la camaraderia, de l'altra. La possessió d'uns valors sòlids o la potència dels sentiments són les úniques escales per sortir del pou dramàtic d'uns escenaris terribles o la porta per escapar-se dels entorns on la brutalitat ho empastifa tot.

\section{FEM L'AUTÒPSIA A LES NOVEL-LES I COMPROVEM LES HIPÒTESIS}

Fem un repàs molt breu a les obres per anar comprovant tot el que estem dient. A Abans del silenci ens trobem uns policies que intenten descobrir un crim en una conjuntura impossible: la retirada republicana del 39 i el camí de l'exili. Com diu el mateix Vehí: 


\section{Revista de Filologia}

Així, a Abans del silenci, es reflexiona sobre el fet de ser policia en temps de guerra i del sentit del deure, sobretot quan costa de complir; quan tot al teu voltant s'ensorra, fins l'estat que representes, i s'opta per mantenir, davant la destrucció, la serenitat i el coratge per a continuar essent la representació de la llei i la seguretat. (VEHÍ: 2012b)

Un marc històric on podem trobar de tot menys la coherència i el sentit de la professionalitat que tenen els agents protagonistes, cosa que faria els personatges inversemblants, si no fos perquè els podem interpretar a través de l'entorn ètic que l'Agustí Vehí va creant amb la seva literatura. Però això es pot descobrir a partir de les altres novel.les, perquè, d'entrada - i ho hem de confessar-, el comportament dels personatges en aquella situació resulta xocant, poc creïble. L'Agustí Vehí, com a escriptor i com a persona, volia que els seus personatges actuessin moguts per una ètica que els fes superar la lògica de la brutalitat històrica.

A Ginesta pels morts. Un blues empordanès, el protagonista - el sergent dels mossos d'esquadra Jaume Planagumà-, la trama - la recerca de la causa d'un seguit d'assassinats-, el temps narratiu i la problemàtica són actuals:

A Ginesta pels morts, en canvi, es parla dels mossos d'esquadra en els moments àlgids del desplegament quan, el projecte de fer una policia nova i democràtica, emocionava $\mathrm{i}$ encisava però trencava parelles, desarrelava agents i feia descobrir a molts joves la complexitat social i cultural de Catalunya o havien de sobreviure enmig d'ambients hostils, com l'Empordà i els empordanesos, sobre tot quan exerceixen com a tals, i algú hi arriba des de la capital. (VEHÍ: 2012b)

Però, a la llarga, l'autèntic protagonista de la novel.la acaba essent un determinat marc històric, i el fil a partir del qual es descobreix tot l'entramat és una cançó popular referida a un període crucial de la història recent. Passat i present, en la trama, no es relacionen, només tenen un lligam per la «materialitat» que ens deixen els esdeveniments d'aquest passat. És com si estiguéssim davant de dos decorats que s'encavalquen. De fet, el protagonista, el sergent mosso, necessitarà, per descobrir els perquès de tots els assassinats, unes «lliçons d'història» que li donaran la gent de la zona a través de la cançó popular i de testimonis i, naturalment, la recerca que fa un agent patruller que estudia història $i$ 
que colllabora a trobar un seguit de fortificacions. En el fons, la novel.la, acaba radiografiant una actuació arqueològica. La investigació policial es serveix de l'anàlisi de la materialitat històrica, del patrimoni, de la resta testimonial que explica coses a qui les hi sap demanar:

Ara ja tenien una visió aproximada del que va ser la postguerra allà dalt: la voluntat de plantar un nou poder en la terra i en les persones. Aquelles construccions inhòspites, abandonades, humides, eren les restes evidents d'un món que ja no existeix, d'una Europa que una vegada i una altra, amb insistència, embogia enmig de guerres civils entre europeus. Eren el record físic d'una catàstrofe, un record al qual ara, una investigació policial, posava veus i noms. (VEHÍ: 2010, 218)

El fil argumental el descobreix el sergent, el protagonista, però la novel.la ens mostra uns personatges entranyables que l'acompanyen, fidels, i, per damunt de tot, uns antiherois plens de normalitat i quotidianitat, cosa que em fa corroborar la tesi de l'Anna Maria Villalonga quan diu que es tracta d'una novel.la de personatges. ${ }^{16}$ La solitud enmig d'una complicitat amable, manyaga, amb un personatge femení — la Meritxell- deliciós.

A Quan la nit mata el dia, la trama s'esdevé en ple franquisme, amb el turment d'una relació amorosa entre un policia que ha de treballar en el règim i una dona marcada personalment pel republicanisme i per la violència del franquisme. Joc de contraris on sempre emergeixen les persones en majúscula, els bons $i$ els dolents, estiguin al bàndol que estiguin i siguin del cos policial que siguin. Un destí —la història protagonista- els arrossega tots; però no en són titelles, perquè l'ètica personal i els sentiments els salven, els fan ser bons, malgrat el que es vegin obligats a fer. Per l'autor:

\footnotetext{
${ }^{16}$ "Ginesta pels morts m'ha semblat per damunt de tot una novel.la de personatges. La construcció dels protagonistes és magnífica, però també ho és el dibuix a pinzellades de l'estol de tipus secundaris que Vehí ens regala. Gent de l'Empordà profund, amb les seves misèries $i$ les seves grandeses. Un humor fi, de vegades irònic, de vegades crític, però sempre ple de tendresa, ens introdueix en un món que hom pot intuir quan es considera fill adoptiu d'aquesta terra, però que només els de dins són capaços de copsar en tota la seva complexitat» (VILLALONGA, 2011).
} 
A Quan la nit mata al dia, s'intenta explicar les formes que pot tenir la policia en una dictadura, les relacions d'aquesta amb la població i la reconstrucció de les histories personals després d'un desastre tan gran com va ser la guerra civil. Es parla dels sentiments quan es barregen amb la feina i del procés d'integració, o no, dels policies que venien de fora. (VEHÍ: 2012b)

I un concepte que acabem de llegir i que, al nostre entendre, resulta clau: «la reconstrucció de les persones després d'un desastre», una reconstrucció que només es pot fer a través de l'amor. I per això la història d'amor entre els protagonistes — «En Carlos i la Glòria es veien d'amagat a casa d'ella, quan tot era fosc, quan els carrers eren buits, quan tothom ja era a casa» (VEHÍ: 2011, 9)—, és un procés lent de començar de nou, de trencar amb un passat trist i un present esgarrifós. El personatge femení, segons l'Àlex Martín, «conjumina de manera magistral un equilibri entre l'amor i la tragèdia» (MARTÍN: 2012, 14). Aquest trobarse entre uns llençols de manera clandestina esdevé, alhora, l'única llum que fa que els amants puguin superar el passat, encarin el present $\mathrm{i}$ arribin a dibuixar un futur en pau. I això que, fora d'aquesta quotidianitat clandestina i plena de tendresa, només hi ha grisor. «Retrat de la grisor», qualifica Sebastià Bennasar aquesta obra, on «Figueres es converteix, així, en un exemple extraordinari de la foscor de la postguerra en general a tot Catalunya i per extensió a tota Espanya» (BENASSAR; 2012).

A Remor de serps, la darrera novel.la, pòstuma, de l'autor, ens indica el mateix: una combinació de personatges — guàrdia civil, inspector de policia, anarquistes, policies francesos- que es troben i que interactuen en el París on ha anat a recaure l'exili català, i espanyol, i que s'enfronten a la brutalitat dels agents de l'ambaixada de Franco. De fet, a part del context històric és un al.legat antifeixista. També el sentit ètic dels agents policials, identificats amb els postulats democràtics que la Segona República significava, és el que els fa ser, malgrat ser uns perdedors, dipositaris de l'esperança que el malson del totalitarisme a la llarga acabarà. Una posició ben estranya en un París atrapat i en una Europa que haurà de viure l'Holocaust, sense cap mena de dubte un dels processos més sanguinaris de la història de la humanitat.

Una consideració un xic diferent tindria l'obra Torn de nit. Un vodevil negre i policial a l'empordanesa, l'última publicada en vida de l'autor i 
que, segons ell, «explica, de manera irònica però entranyable, les cabòries de les velles generacions de policies enmig d'un món informatitzat i globalitzat, que ja no entenen, i del contrast d'aquests agents amb les noves promocions que saben molt de màquines però res de la vida. » (VEHÍ: 2012b) En totes les novel-les la ironia hi és present, però en aquesta séns presenta d'una manera excelsa. ${ }^{17}$ Llegir-la és fer-se un tip de riure per les situacions, pels personatges, per les sortides i per les imatges plàstiques. Sens dubte, és la novel.la més teatral, la que amb més facilitat podria representar-se, amb la qual cosa no sé si podríem parlar que ens trobem davant d'una trama caracteritzada de tal manera que ben bé podria passar a un escenari només que algú la hi volgués transportar. De fet, l'autor ja hi va posar en el títol, Un vodevil negre $i$ policial, tenint en compte que hi té una retirada pels embolics. Però, i potser és un atreviment plantejar-ho, a nosaltres ens recorda encara més un gènere molt important a casa nostra i molt popular com són els Pastorets. ${ }^{18} \mathrm{~A}$ l'obra hi ha un treball que tothom ha destacat $i$ és aquest tractament tan exquisit del parlar popular dels agents entre els castellanismes i els empordanismes ${ }^{19}$. Ara, per a nosaltres, és insuperablement divertida la definició de Vilaclara - Figueres - que fa al principi de l'obra i que té, com no, unes clares referències històriques:

\footnotetext{
${ }^{17}$ Sobre l'humor i la ironia en la novel-la negra, he trobat molt suggeridora la referència que fa Àlex Martín a Raymond Chandler quan afirmava que «narrant successos violents el novel-lista té l'obligació d'allunyar al lector de l'horror i la millor manera de fer-ho és a través de l'humor», cosa que li fa afirmar a l'Àlex Martín que l'Agustí Vehí dóna sempre la dosi exacte d'humor i d'ironia. (MARTín: 2012, 14).

${ }^{18}$ La vinculació de l'Agustí Vehí amb els pastorets és sabuda per qui el coneixia i, a més, n'havia escrit la història publicada en el llibre: Agustí Vehí, Alfons Gumbau i Gemma Gumbau, Els pastorets de Figueres' Edicions del Brau. 1998.

${ }^{19}$ El tema de la llengua era una preocupació i un motiu de reflexió per Agustí Vehí i per això afirmava: «Però també representa, per qui escriu, un repte apassionant: construir, o reconstruir, una llengua policial i delinqüencial en català que sigui natural, fresca, creïble, de carrer. I, a vegades, no és fàcil però sempre és una feina interessantíssima. A la quarta novel.la, a Torn de nit, el rerefons no és històric però, precisament, una bona part de les ironies venen dels aspectes idiomàtics i de la dificultat dels agents més grans per expressar-se en el seu propi idioma degut a l'educació rebuda. » (VEHÍ: 2012,b)
} 
Vila gran i sàvia a peu d'una frontera que si tén vas fa pujada i cansa, i si tornes fa baixada i t'entrebanques, la gent de Vilaclara, com la de Sóller de Mallorca, ha vist de tot i sap que tot passa: els que s'havien de menjar el món corren al cap de quatre dies cap a França camí de l'exili, empaitats pels que emplenaven les presons feia exactament els mateixos quatre dies. Els invasors que entraven a tocs de tabal a imposar qualsevol bestiesa són els que al cap d'un tres i no res tornen a passar en direcció contrària amb el tabal per barret. Res de res, diuen els vilaclarencs, tot plegat és una bona tocada de collons $i$, convençuts d'aquesta veritat immutable, es dediquen, acte seguit, al capítol de coses importants, demanant que hi ha per dinar. (VEHÍ: 2012a, 13)

\section{QUAN PASSEN LES COSES I ON PASSEN}

El marc històric rellevant, el decorat adient i l'espai temporal en què es mouen les trames en totes les novel.les és, predominantment, aquell moment del xoc entre el republicanisme i la dictadura, entre la Guerra Civil i el primer franquisme, entre el feixisme-nazisme i la democràcia. ${ }^{20} \mathrm{O}$ sigui, entre la nit i el dia, entre la brutalitat i la consciència, entre la submissió i la llibertat. Podem comprovar com els personatges es divideixen - siguin quins siguin i sigui quin sigui el cos policial a què pertanyen - entre aquells que representen la nit, la brutalitat i la submissió i aquells que representen el dia, la consciència i la llibertat. L'Agustí Vehí, pels coneixements científics que tenia, delimita bé les situacions històriques, parla amb propietat dels fenòmens, no cau en errors històrics, sap escenificar amb autenticitat les conjuntures i domina les cronologies i els temps dels esdeveniments, cosa que, d'altra banda, i encara que no sigui tan freqüent, també podríem trobar en d'altres novel.listes:

- Tan dur va ser allò, parlo de la guerra...

-A què et refereixes exactament? A la pròpia guerra, a la reculada, amb el pas de frontera de milers d'homes, dones, nens... o després, quan tot havia acabat? Si la primera cosa va ser un desastre, la segona va ser un drama que encara el tinc als ulls i la tercera... Vols saber que va passar a l'arribada dels nacionals, en el

\footnotetext{
${ }^{20}$ L'autor ho explicita perfectament quan diu: «Per això, tres de les novel-les tenen una clara voluntat d'explicar aquesta història recent. Els seus respectius telons de fons són els mesos finals de la guerra, en la primera; després els batallons de penats i treballadors i el treball forçat de la primera postguerra a l'altre o, finalment, la Figueres dels anys cinquanta i la vida grisa i fosca que hi havia, a l'última.» (VEHÍ: 2012,b).
} 
primer moment, quan va començar la cacera de les persones i els afusellaments sense més tràmit o la seva conducció a Figueres, a la Carbonera, per a la classificació política i, segons aquesta, anar aquí i allà, és a dir, a la mort, al consell de guerra, a la presó, al batalló de treball o al servei militar, o, els més afortunats a casa? O vols dir després, quan va començar la reconstrucció de ponts i camins i la construcció de defenses, per part dels presoners de guerra i, després, pels batallons de treballadors...? Els primers moments de la postguerra van ser horribles, homes vells i nois joves barrejats, dormint al ras o en tendes de campanya, treballant a pic i pala i mirant de caçar alguna serp o algun llangardaix per menjar... Tot plegat... Tot plegat res, noi, misèria, pura misèria; ja tho he dit: un gran desastre. (VEHÍ; 2010, p. 177)

Però si hi ha una cosa que l'autor dibuixa a la perfecció és la història dels cossos policials - i podem afegir-hi els militars- i el seu tarannà en cada moment històric, un coneixement forjat a partir de les lectures - amb una biblioteca-arxiu personal sobre temes de seguretat molt important- i de la pròpia recerca científica.

Per què aquesta fascinació per aquest moment històric? Per què, en totes les novel.les, ens apareix aquest marc temporal que anirà del 1936 fins als anys centrals del franquisme? És difícil respondre a aquestes qüestions, però aventuraré unes hipòtesis. Una d'agosarada és l'impacte que sobre l'autor té la pròpia tradició familiar i els relats orals de moltes persones que van viure el període. Una segona hipòtesi seria l'especial protagonisme de l'Empordà en aquest context històric. Aquí entrem en una temàtica historiogràfica, que normalment no sol sortir i queda reclosa entre els especialistes, i és el fet que la guerra civil i la postguerra immediata tenen unes característiques determinades i diferenciades depenent del marc geogràfic en què s'esdevinguin. Hi ha una «geografia de la guerra» que $f a$ que les poblacions, encara que visquin fenòmens semblants, pateixin unes conseqüències molt diverses. Per exemple, viure la guerra a Galícia, on va triomfar el cop militar d'entrada, o viure-la a Madrid, que va ser un front durant tots aquells anys, o viure-la a Catalunya, que era la rereguarda, representa una vivència diferent. L'Alt Empordà serà el protagonista d'un cert tipus de guerra, el del moment final, el del coll d'embut per on han de passar, en poc temps, les últimes resistències, els exiliats, els diferents governs; tot plegat, en una geografia plana i abrupta alhora, en una ciutat, com Figueres, que representa 
l'últim punt important de defensa, d'atac, de subministrament, d'acomiadament i de tot alhora. Una geografia i uns moments històrics que porten Walter Benjamín a suïcidar-se a Portbou davant la possibilitat de ser lliurat pels franquistes a la França col-laboracionista. I no cal que recordi l'escenari geogràfico-històric en què un soldat desconegut en retirada perdona la vida al falangista Rafael Sánchez Mazas, el creador de l'expressió «Arriba España» en la novel.la de Javier Cercas Soldados de Salamina. L'Empordà, en aquest sentit, representa un límit, una franja, un punt on tot pot canviar en hores. I això té o representa una càrrega històrica impressionant $\mathrm{i}$ una força literària indubtable. Per aquest mateix motiu, al meu entendre, i per aquesta mateixa intensitat del moment històric, trobem la fascinació de l'Agustí Vehí pel París que està pràcticament a punt de ser ocupat pels alemanys durant la segona guerra mundial en Remor de serps. A la novel.la, en aquest París hi passen molts esdeveniments en un espai temporal molt breu perquè el seu destí pot canviar en qüestió de poc temps, el temps que pot tardar la Wehrmacht a entrar a la ciutat i desfilar per sota l'Arc de triomphe de l'Étoile. Un París que, en aquells moments i donades les circumstàncies, era com un Empordà. Les comparances són impossibles però la tensió del moment i el significat històric són idèntics. Una novel.la que acaba, en l'últim paràgraf, amb aquesta descripció tan carregada de força i de retrat històric:

$\mathrm{Al}$ vespre, la $\mathrm{BBC}$ diria que, a primera hora d'aquell matí, les tropes alemanyes havien entrat a París, trobant-se una ciutat buida i silenciosa, amb molt poca gent al carrer. Qui no havia marxat a temps, era a dins de casa amb les persianes baixades, les finestres tancades i les cortines posades. (VEHÍ: 2013, 224).

Però hi ha un altre element que té Figueres i que és molt important: és i representa una frontera, amb la càrrega literària que això comporta. Una frontera que significa el punt on finalment es fa justícia, a Abans del silenci; o des d'on es controla la possible subversió que ve de França, a Quan la nit mata al dia; o el punt estratègic des d'on es poden produir tota mena de drogues per part de màfies internacionals, a Ginesta pels morts. Però és que, a més, el fet de ser frontera possibilita la concen- 
tració de tot tipus de policia $i$, en certs moments històrics, de l'exèrcit, tots ells protagonistes centrals de l'obra de l'Agustí Vehí. El to de la guerra i la postguerra queda perfectament dibuixat en un diàleg entre el sergent dels mossos i un vell:

-Ai, fill meu! El trenta-nou aquestes muntanyes semblaven la Rambla de Figueres per la Santa Creu. Després, amb els nacionals instal.lats, hi havia la mateixa gent però amagada; llavors va començar el gran joc. Però no vull parlar d'això; aquests caminois i corriols, aquestes clarianes i alzinars, cada roure, amaguen històries, estan plenes d'un passat que a vegades torna... ${ }^{21}$ (VEHÍ: 2010, 176).

L’Agustí Vehí tenia una fascinació pels llocs que ens representen i ens expliquen contrastos, que ho són tot i que no són res, que poden fer córrer una imaginació ben real i concreta. I, en aquest sentit, el castellfortalesa de Sant Ferran de Figueres és la culminació de tot el que diem. Una fortalesa descomunal i molt ben pensada militarment que, pràcticament, no entra mai en guerra. Però un espai que sempre hi és, on hi passa de tot i que esdevé el cronista de la ciutat; unes pedres que dominen la ciutat sense que a la vila $i$ als visitants séls faci tan evident. Un dels primers aperitius literaris d'Agustí Vehí foren les VIII Rondalles napoleòniques: que contenen la relació exacta i precisa dels secrets més grans que amaga el Castell de Sant Ferran de Figueres, tots mentida, certament, però que van passar en els termes justos i precisos que a continuació s'expliquen minuciosament, uns textos de base històrica però plens de fantasia, on el castell de Figueres n'és el protagonista essencial. Sense la fascinació pel

\footnotetext{
${ }^{21}$ En aquest sentit Enric Pujol ens diu: "Tanmateix, val la pena remarcar el paper referencial que durant el règim republicà jugà Figueres en el conjunt de ciutats de Catalunya. La Guerra Civil del 1936-1939 i la derrota republicana van marcar el declivi del mite en la seva forma originària. Tanmateix, durat el període final del conflicte, Figueres adquirí un altíssim valor simbòlic, com mai no havia obtingut abans. Durant la retirada del 1939 fou la darrera capital republicana de Catalunya i la seu de tres governs: el central de la República, el de la Generalitat de Catalunya i el govern basc. Així, fou en aquesta ciutat on se celebraren les darreres Corts republicanes (al castell de Sant Ferran), on Companys féu el seu darrer míting al Principat de Catalunya, on passaren milers i milers de persones camí de l'exili i on, després de Barcelona, més morts per bombardeig hi hagué, en xifres absolutes." (PUJOL: 2013, 27).
} 
castell i sense aquestes rondalles, l'obra de l'Agustí Vehí no hagués agafat el vol i no hauríem tingut l'escriptor que tenim ara, malgrat l'opinió que tenia d'ell mateix:

En qualsevol cas, he de reconèixer que tinc problemes per dir que faig literatura, no m'atreveixo, no sóc tan bo i tothom ha de saber els seus límits. Com tampoc em penso, a mi mateix, com a escriptor, és una paraula molt grossa i honorable i són els altres és que han de fer-la servir, no jo. Per pura humilitat, per pur respecte a altres persones que escriuen i que no han tingut la sort de publicar i jo, amb només quatre novel.les, no sembla que hagi de sortir a cap manual de literatura catalana contemporània. El plaer de llegir, el plaer d'explicar històries i el plaer d'escriure. La realitat. D'acord, però, escric amb alguna finalitat més enllà del gust de fer-ho? És evident que sí (...) una de les finalitats més clares del que escric es mostrar que darrera cada uniforme, encara que ha vegades costi de veure, hi ha una persona. Que no som policies de sèrie americana o de pel.lícula, que tenim família, sentiments i problemes. (...)

Persones i policies, sempre, en diferents moments i sota diverses circumstàncies. Persones d'uniforme o amb placa i amb la seva història a sobre. Comptat i debatut, escric sempre una reflexió, no tant sobre la policia, com de les persones que formen la policia. (VEHÍ: 2012b)

\section{PER FI, JA HeM TROBAT EL CULPABLE}

La història com a ciència que fonamenta la literatura de l'Agustí Vehí, la història que és una protagonista i que, alhora — i segons la tesi que voldríem defensar - marca les vicissituds dels personatges que només se salven d'un destí inexorable per la seva ètica i pels seus sentiments. Uns personatges que, en definitiva, són perdedors, o que esdevenen herois sense ressò. No ens trobem - $\mathrm{i}$ ho preguntem amb una mica de por i de recel- davant la pròpia veritat de l'autor? La seva pròpia història? L'intel-lectual, el policia, l'historiador, el novel.lista, el que volia el dia, la consciència i la llibertat, i que, com els homes de la seva tesi, anhelava aquesta «revolució inabastable». L'escriptor figuerenc que, en definitiva, i enmig de la seva conjuntura històrica, esdevé un «perdedor»: perquè no acaben de guanyar ni el seu model de societat ni el seu model de policia pel qual va lluitar tant.

Perdedors i guanyadors, quin debat més interessant i literari! No deixa de ser curiós un paràgraf de la seva tesi doctoral, quan ens explica i 
ens retrata quins són els realment guanyadors, en aquest cas de totes les vicissituds històriques del segle XIX en la construcció del nou estat:

Aquests homes que acaben guanyant en la lluita per construir el nou estat, aquests gattopardi a l'empordanesa, doncs, sembla que donen tot el procés de construcció per acabat entre la fi de la primera guerra carlina i el Bienni; sembla, també, com la revolució del 1868, relativament controlada des del principi, els anés bé per guanyar les incòmodes restes de la carlinada, gràcies a la carn de canó motivada de la Milícia, deixant la direcció d’aquests assumptes més molestos, vistos com a menors en relació amb l'acumulació de riquesa, en mans dels republicans $i$, un cop la feina està feta, tornen al que perceben com el seu lloc natural, és a dir, al poder. Els altres, el poble en general i la seva part més conscienciada políticament, els republicans, també tornen, sempre des de la perspectiva dels primers, al lloc que els pertoca, és a dir, a l'exili, al cafe o al jornal. (VEHÍ: 2008, 251)

Ara, realment podem considerar l'Agustí Vehí com un perdedor? Segurament no; perquè, com els seus personatges, el sentit de l'ètica el situà per damunt d'aquells que el van guanyar i la força dels seus sentiments per sobre dels soldadets de plom que el sistema ha anat configurant.

Les novel.les de l'Agustí retraten un món de ficció, amb base real. I el que encara és més important: són un reflex d'ell mateix i la seva vida. Acaben dibuixant aquest humanista intel-ligent, irònic, amb un gran sentit del deure, teatral, afable, confident: en última instància, un volterià.

Sóc, simplement, un guàrdia urbà a qui li encanta explicar històries i que, a més a més, troba en l'acte d'escriure un gran plaer personal. M'agrada. (VEHí: 2012b).

\section{BIBLIOGRAFIA}

BENNASAR, Sebastià (2012): Ressenya Agustí Vehí, «Quan la nit mata el dia. Retrat de la grisor» 15-2-2012. http://www.crims.cat/cat/ ressenyes/8/Agusti-Vehi-Quan-la-nit-mata-el-dia.html (data de consulta: 15 de desembre 2013).

HoBSBAWM, Eric (1995): Historia del siglo XX, Barcelona, Crítica.

MARTín, Àlex (2012): «Quan la nit mata el dia, d'Agustí Vehí» Caràcters, núm. 58, p. 14. 
PujOL, Enric (2013): «Iniciació al mite de Figueres» en Oscar Jané i Xavier Serra (eds.) Ultralocalisme. D'allò local a l'universal, CatarrojaFigueres-Perpinyà, Mirmanda - Editorial Afers.

VEHÍ, Agustí et al. (1990): Els pastorets de Figueres, Figueres, Edicions del Brau.

VEHÍ, Agustí (2001): «D’Urbanos, grans superfícies i models policials» El Punt (juliol). http://webpolicial.info/portal/index.php?option= com_content $\&$ task $=$ view $\&$ id $=658 \&$ Itemid $=2$ (data de consulta: 10 de desembre 2013).

- (2003): VIII Rondalles napoleòniques: que contenen la relació exacta $i$ precisa dels secrets més grans que amaga el Castell de Sant Ferran de Figueres, tots mentida, certament, però que van passar en els termes justos $i$ precisos que a continuació s'expliquen minuciosament, Figueres, Fundació Privada Cultural Les Fortaleses Catalanes.

- (2008): Torna el fusell i posa't a treballar. La Milícia Nacional a Figueres a la darrera guerra carlina (1872-1876), Figueres, Ajuntament de Figueres, col-lecció Juncària.

- (2009): Abans del silenci, Lleida, Pagès editor.

- (2010): Ginesta pels morts. Un blues empordanès, Perpinyà, Éditions Mare Nostrum.

- (2011): Quan la nit mata el dia, Barcelona, La Magrana.

- (2012a): Torn de nit, Un vodevil negre i policial a l'empordanesa, Barcelona, Ed. Alrevés.

- (2012b): «La realitat impresa i uniformada: quan un policia escriu (amb el permís de l'alegre colla d'assumptes interns!) ». Text (no publicat) de la xerrada que va fer a l'Institut de Ciències Polítiques i Socials de Catalunya (ICPSC) de Barcelona, en el grup de recerca sobre seguretat dirigit pel Dr. Jesús M Rodés, l'1 de febrer del 2012.

- (2013): Remor de serps, Barcelona, Ed. Alrevés

VillalongA, Anna Maria (2011): «Ginesta pels morts, d’Agustí Vehí» 12 d'agost de 2011, http://alombradelcrim.blogspot.com.es/2011/ 08/ginesta-pels-morts-dagusti-vehi.html (data de consulta: 22 de novembre de 2013). 